\title{
Clues to a possible new variant of thyroid hormone resistance
}

Jens P Berg

Hormone Laboratory, Aker University Hospital, Trondheimsveien 235, N-O514 Oslo, Norway

Patients with thyroid hormone resistance, first described by Refetoff et al. in 1967 (1), usually present with goitre, elevated thyroid hormone levels and an inappropriately normal or elevated thyrotrophin (TSH) level (reviewed in $2,3)$. Clinical effects of thyroid hormone resistance can include variable features of hypo- and hyperthyroidism such as tachycardia, attention deficit/hyperactivity disorder, growth retardation and hearing defects. The syndrome is known to be caused by mutations in the thyroid hormone receptor (TR) $\beta$ gene, but the molecular basis of cases without mutations in this gene remains elusive, and no mutations have ever been found in the $\alpha$ gene of the receptor (TR $\alpha)$. A recent study by Wikström et al. (4) indicates that there may be another variant of resistance to thyroid hormones with a different clinical presentation caused by defects in $\operatorname{TR} \alpha$.

TRs are ligand-modulated transcription factors and the products of two different genes (reviewed in 5,6). The TR $\beta$ gene in chromosome 3 encodes two receptor isoforms (TR $\beta 1$ and TR $\beta 2$ ), which are splice variants. Proteins encoded by the $\mathrm{TR} \alpha$ gene in chromosome 17 include one receptor that binds thyroid hormones (TR $\alpha 1$ ), two isoforms that bind thyroid hormone responsive elements on DNA, but do not bind thyroid hormones (TR $\alpha 2$ and $\mathrm{TR} \alpha 3)$, and one structurally related orphan receptor encoded by the opposite DNA strand $($ rev-erbA $\alpha)$. The first case of thyroid hormone resistance showed an autosomal recessive pattern of inheritance and lacked not only the $\operatorname{TR} \beta$ gene, but also adjacent sequences (7). In all other familial cases there is an autosomal dominant inheritance pattern. Mutations have been demonstrated in the $\mathrm{TR} \beta$ gene resulting in a receptor with a dominant negative effect of the mutated receptor protein on normal TR function. This has also been shown in sporadic cases of thyroid hormone resistance.

It has been speculated that TR $\alpha$ gene mutations in humans would be incompatible with early foetal survival or give rise to clinical features not associated with the recognized form of thyroid hormone resistance. In mice, homozygous inactivation of the $\mathrm{TR} \alpha$ gene, which abrogated the production of the TR $\alpha 1$ and TR $\alpha 2$ isoforms, led to hypothyroidism, growth arrest and death within 5 weeks after birth (8). Wikström et al. (4), at Björn Vennströms laboratory at the Karolinska Institute in Stockholm, wanted to identify effects of thyroid hormones specifically mediated by TR $\alpha 1$. A transgenic mouse, which lacked a functional TR $\alpha 1$, without losing TR $\alpha 2$ and rev-erbA $\alpha$ expression, was developed. They demonstrated that deletion of TR $\alpha 1$ did not affect viability of the mice, and there was a normal ratio between male and female offspring. Homozygous animals survived to at least 18 months of age, and both sexes were fertile with normal litter sizes. No overt abnormalities were discovered at autopsy, and no compensatory increase in the expression of the other thyroid hormone receptors was detected in the brain. In contrast to the increase in thyroid hormone levels observed in thyroid hormone resistance, TR $\alpha 1$ deficient mice had lower serum levels of free thyroxine $\left(\mathrm{T}_{4}\right)$ than the controls, whereas the levels of free tri-iodothyronine $\left(\mathrm{T}_{3}\right)$ were not statistically significantly different. In male TR $\alpha 1$ deficient mice, serum TSH levels were lower than in the control mice. Northern blot analyses of pituitaries from these animals revealed that the mRNA levels of the TSH $\alpha$ subunit were reduced in mice without $\operatorname{TR} \alpha 1$, whereas the $\beta$ subunit was increased. Although a reduction in the glycoprotein hormone $\alpha$ subunit mRNA was associated with a reduction in the TSH level, there was no effect on luteinizing hormone, chorionic gonadotrophin and follicle-stimulating hormone function since sexual maturation and fertility were unaffected. However, mice lacking both $\mathrm{TR} \alpha 1$ and $\mathrm{TR} \alpha 2$, became severely hypothyroid, their pituitary mRNA level of the TSH $\beta$ subunit was lower than in the control mice, and their thyroid glands were hypoplastic (8). Hypothyroidism seems to induce the expression of TSH $\alpha$ subunit mRNA in the pituitary not only by removing a passive repression induced by thyroid hormones, but also by transcriptional activation through $\operatorname{TR} \alpha 1$. Studies of $\operatorname{TR} \beta$ deficient mice indicate that $\mathrm{TR} \beta 2$, which is highly expressed in thyrotrophs of the pituitary, is essential for a normal inhibition of TSH production by thyroid hormones $(9,10)$. However, a normal feed-back regulation of thyroid hormones on TSH production also depends on a normal TR $\alpha$ gene. In the TR $\alpha$ gene knock-out mouse models a functional $\mathrm{TR} \alpha 2$ is associated with a less severe hypothyroidism $(4,8)$, which indicates that $\operatorname{TR} \alpha 2$ attenuates the inhibitory effects of TR $\beta 2$ on TSH production.

The syndrome of thyroid hormone resistance is often accompanied by tachycardia. In TR $\alpha 1$ deficient mice, heart rate was slower than in control mice even after prolonged treatment with $\mathrm{T}_{3}$ (4). Both $\mathrm{TR} \alpha 1$ and $\mathrm{TR} \beta$ are expressed in mouse heart (11). To some degree the effects of thyroid hormones on pacemaking functions in the heart are mediated by $\operatorname{TR} \beta$ in $\operatorname{TR} \alpha 1$ deficient mice. The molecular basis of the bradycardia induced by TR $\alpha 1$ deficiency has not been revealed, but may be mediated by modulating the effects of $\beta$-adrenergic or muscarinic receptor activation in the cardiac sinoatrial node or the expression of ion channels and pumps. However, the levels of well-known myocardial target genes for thyroid hormones, such as the sarcoplasmic 
$\mathrm{Ca}^{2+}$-ATPase, $\mathrm{Na}^{+}-\mathrm{K}^{+}$ATPase, and $\beta$-adrenergic receptor, were not changed. Electrocardiograms corrected for the differences in heart rate revealed that the QRSduration was prolonged. This is also observed in hypothyroid rat myocytes and in hypothyroid patients. The $\mathrm{QT}_{\text {end }}$ duration was also longer, which is associated with a prolonged ventricular repolarization time. The bradycardia and electrocardiographic changes indicate that there may be genes that are specifically regulated by TR $\alpha 1$ in the heart. However, the partial $\mathrm{T}_{3}$ resistance in the TR $\alpha 1$ deficient mice heart may simply be the result of a lower total number of TRs in this tissue.

$\mathrm{TR} \alpha 1$ deficiency was associated with a $0.5^{\circ} \mathrm{C}$ reduction in body temperature when compared with the control mice (4). There were no changes in locomotor activity, and the amount of brown fat was the same. After $\mathrm{T}_{3}$ treatment the temperature increased in the TR $\alpha 1$ deficient mice, but was always lower when compared with the similarly treated controls. Both $\mathrm{TR} \alpha 1$ and TR $\beta$ s seem to be important for thermogenesis in brown fat or in other processes regulating body temperature. As for the bradycardia, the hypothermia may depend on a lower total number of receptors rather than a specific deficiency in TR $\alpha 1$ signalling.

The mouse model created by Wikström et al. (4) illustrates a situation where TSH is not a good measure of thyroid hormone status. It is important that the clinician has an open mind when dealing with thyroid patients with laboratory and clinical discrepancies. A patient with slight hypothermia, bradycardia, and low serum levels of TSH and free $\mathrm{T}_{4}$ may have a thyroid hormone resistance caused by a dysfunctional TR $\alpha 1$.

\section{References}

1 Refetoff S, DeWind LT \& DeGroot LJ. Familial syndrome combining deaf-mutism, stippled epiphyses, goiter, and abnormally high PBI: possible target organ refractoriness to thyroid hormone. Journal of Clinical Endocrinology and Metabolism 196727279 294.

2 Refetoff S, Weiss RE \& Usala SJ. The syndromes of resistance to thyroid hormone. Endocrine Reviews $199314284-335$.

3 Chatterjee VKK. Resistance to thyroid hormone. Hormone Research 199748 43-46.

4 Wikström L, Johansson C, Saltó C, Barlow C, Barros AC, Baas F et al. Abnormal heart rate and body temperature in mice lacking thyroid hormone receptor $\alpha 1$. EMBO Journal $199817455-461$.

5 Lazar MA. Thyroid hormone receptors: multiple forms, multiple possibilities. Endocrine Reviews 199314 184-193.

6 Muñoz A \& Bernal J. Biological activities of thyroid hormone receptors. European Journal of Endocrinology 1997137 433-445.

7 Takeda K. Sakurai A, DeGroot LJ \& Refetoff S. Recessive inheritance of thyroid hormone resistance caused by complete deletion of the protein-coding region of the thyroid hormone receptor- $\beta$ gene. Journal of Clinical Endocrinology and Metabolism 199274 49-55.

8 Fraichard A, Chassande O, Plateroti M, Roux JP, Trouillas J, Dehay $\mathrm{C}$ et al. The $\mathrm{T} 3 \mathrm{R} \alpha$ gene encoding a thyroid hormone receptor is essential for post-natal development and thyroid hormone production. EMBO Journal 199716 4412-4420.

9 Forrest D, Hanebuth E, Smeyne RJ, Everds N, Stewart CL, Wehner JM et al. Recessive resistance to thyroid hormone in mice lacking thyroid hormone receptor beta: evidence for tissue-specific modulation of receptor function. EMBO Journal $1996153006-$ 3015.

10 Weiss RE, Forrest D, Pohlenz J, Cua K, Curran T \& Refetoff S. Thyrotropin regulation by thyroid hormone in thyroid hormone receptor $\beta$-deficient mice. Endocrinology $19971383624-3629$.

11 Schwartz HL, Lazar MA \& Oppenheimer JH. Widespread distribution of immunoreactive thyroid hormone $\beta 2$ receptor $(\mathrm{TR} \beta 2)$ in the nuclei of extrapituitary rat tissues. Journal of Biological Chemistry 1994269 24777-24782. 